ISSN 1984-3755

Licenciado sob uma Licença Creative Commons

\title{
El Vaticano II en medio del conflicto de interpretaciones ${ }^{1}$
}

\author{
O Vaticano Il em meio ao conflito de interpretações
}

\section{Víctor Codina}

Doutor em Teologia pela Pontifícia Universidade Gregoriana, Roma; mestre em Teologia pela Faculdade de Teologia da Universidade de Innsbruck, Áustria; professor de Teologia no Instituto Superior de Estudos Teológicos da Universidade Católica Boliviana de San Pablo, Cochabamba Bolívia, e-mail: victorcodina@yahoo.es

\section{Resumen}

El autor examina el conflicto de las interpretaciones que ponen en el Vaticano desde una perspectiva latinoamericana. Su trabajo se organiza en tres fases: el Consejo como un nuevo Pentecostés que promueve una transición epocal en la comprensión de la Iglesia y su misión en el mundo (parte 1), el hecho de que ciertas perspectivas - afirmó, incluso por el consejo, pero no está haciendo su líneas de fuerza y el dinamismo profundo - ocupan un lugar privilegiado en la presentación de la identidad de la Iglesia y su lugar en la sociedad (parte 2), el hecho de que, cincuenta después de la inauguración del Consejo, un nuevo contexto histórico y generación, ha como si no hubiera un

1 Artigo publicado inicialmente em Mirada global.com Revista on-line desde Latinoamérica (7, 14 e 21 de abril de 2011) cedido pelo autor para publicação na Revista Pistis \& Praxis. 
cambio de acento e interés en y el aprecio de los textos conciliares en la actualidad. El mayor cambio se estaba produciendo en el paso de los temas eclesiológicos - el Consejo, simplemente, fue un concilio de la Iglesia - con el tema realmente teo-lógico. En este mundo gira desde lo más profundo de sus entrañas transformaciones radicales en todos los ámbitos y niveles de la actividad humana, la pregunta no es "la Iglesia, ¿qué dices de ti mismo?" E "Iglesia, ¿qué haces en el mundo?” pero “Dios, ¿quién eres tú?", "lo que tiene que decir a los hombres y mujeres liberados en los retos personales y colectivos sin precedentes?" caos también kairós y puede llegar a ser en gestación una Iglesia renovada, Nazareno, más pobre, servidor

Palabras-clave: Consejo. Transición. Ambigüedades. Los cambios de acento.

\section{Resumo}

O autor analisa o conflito de interpretações a que é submetido o Vaticano II desde uma perspectiva mais latino-americana. Seu trabalho está organizado em três momentos: o Concílio como novo Pentecostes que promove uma transição epocal na compreensão da lgreja e da sua missão no mundo (primeira parte); o fato de certas perspectivas - afirmadas, sim, pelo Concílio, mas não constituindo suas linhas de força e seu dinamismo profundo - assumirem um lugar privilegiado na apresentação da identidade da lgreja e de seu lugar na sociedade (segunda parte); a constatação de que, 50 anos depois da inauguração do Concilio, num novo contexto histórico e geracional, tem havido como que um deslocamento de acentos e de interesse na apreciação e na atualidade dos textos conciliares. O maior deslocamento estaria ocorrendo na passagem da temática eclesiológica - o Concílio, simplificando, foi um concílio sobre a lgreja - para a temática propriamente teológica. Neste mundo, revolvido desde as suas entranhas mais profundas por transformações radicais em todos os âmbitos e niveis da atividade humana, a pergunta não é mais "Igreja, o que dizes de ti mesma?" e "Igreja, o que fazes no mundo?", mas “Deus, quem és?", "o que tens a dizer a homens e mulheres lançados diante de desafios pessoais e coletivos sem precedentes?" Também o caos pode se revelar kairós e gestar uma Igreja renovada, nazarena, mais pobre, servidora.

Palavras-chave: Concílio. Transição. Ambiguidades. Mudanças de acento. 


\section{Un verdadero Pentecostés}

El deseo y oraciones de Juan XXIII, que pedia que el Vaticano II fuera un Pentecostés para la Iglesia, fue ampliamente escuchado por el Señor. El Vaticano II fue una auténtica irrupción del Espíritu sobre la Iglesia, un acontecimiento salvífico, un verdadero kairós. Hay un "antes" y un "después" del Vaticano II.

Este tema ha sido tan ampliamente estudiado ${ }^{2}$ que bastará recordar las líneas fundamentales del cambio producido en el Concilio:

- de la Iglesia de Cristiandad, típica del Segundo milenio, centrada en el poder y la jerarquía, se pasa a la Iglesia del Tercer milenio que recupera la eclesiología de comunión típica del Primer milenio y se abre al desafío de los nuevos signos de los tiempos (GS 4; 11; 44).

- de una eclesiología centrada en sí misma, se abre a una Iglesia orientada al Reino, del cual Iglesia es, en la tierra, semilla y comienzo (LG 5).

- de una Iglesia sociedad perfecta, tan visible e histórica como la república de Venecia o el Reino de los francos (Roberto Belarmino), se pasa a una Iglesia misterio, radicada en la Trinidad, una muchedumbre congregada por la unidad del Padre, del Hijo y del Espíritu Santo (LG 4).

- de una eclesiología exclusivamente cristocéntrica (incluso "cristomonista" según la formulación de teólogos del Oriente), se pasa a una Iglesia que vive tanto bajo el principio cristológico como bajo el principio pneumático del Espíritu, quien la rejuvenece, la renueva y la conduce a la unión consumada con Cristo (LG 4).

- de una Iglesia centralista, a una Iglesia corresponsable y sinodal que respeta las Iglesias locales, en las cuales y por las cuales existe la Iglesia universal (LG 23).

- de una Iglesia identificada con la jerarquía, a una Iglesia toda ella Pueblo de Dios con diversos carismas y ministerios (LG II).

2 Me permito remitir a mi libro, CODINA, V. Para comprender la eclesiología desde América Latina. Estella Navarra: Verbo Divino, 2008. Nueva edición actualizada. 
- de un Iglesia triunfalista que parece haber llegado a la gloria, a una Iglesia que camina en la historia hacia la escatología y se llena del polvo del camino (LG VII).

- de una Iglesia señora y dominadora, madre y maestra universal, a una Iglesia servidora de todos y en especial de los pobres, en los que reconoce la imagen de su Fundador pobre y paciente (LG 8).

- de una Iglesia comprometida con el poder, a una Iglesia enviada a evangelizar a los pobres, con los que se siente solidaria (GS 1; LG 8).

- de una Iglesia arca de salvación, a una Iglesia sacramento de salvación (LG 1; 9; 48), en diálogo con las otras Iglesias y con las otras religiones de la humanidad (NA), en pleno reconocimiento de la libertad religiosa (DH).

En este sentido se ha dicho que el Vaticano II y concretamente la constitución Lumen gentium, ha sido un Concilio de transición, entendida esta transición como el paso de una eclesiología tradicional a otra renovada (ALMEIDA, 2005). Para algunos es el paso del anatema al diálogo (R.Garaudy), un verdadero aggiornamento de la Iglesia; para otros, seguramente excesivamente optimistas, el réquiem del Constantinismo ...

\section{Y sin embargo...}

Sin entrar aquí y ahora en lo que ha sucedido en el inmediato y posterior postconcilio, ya el mismo Vaticano II presenta una serie de deficits que lastrarán sus elementos positivos y los ensombrecerán.

Además de que el Vaticano II tuvo que acceder a admitir una serie de enmiendas (o modos) de los grupos más conservadores, que hacen que su eclesiología contenga una cierta ambigua dualidad entre el acento jurídico de la eclesiología tradicional y la afirmación de la eclesiología de comunión (como el teólogo italiano Acerbi ha señalado), el Concilio no trata y guarda silencio sobre temas ya entonces candentes: el celibato sacerdotal y la carencia de ministros ordenados, el papel de la mujer en la sociedad y en la Iglesia, la participación de los seglares en la responsabilidad ministerial, la sexualidad, la disciplina del matrimonio, la forma de elegir a los obispos, 
el estatuto eclesiológico de los obispos auxiliares, de los nuncios y de los cardenales, la función de la curia romana, la relación entre leyes civiles y morales, la relación con las Iglesias orientales separadas de Roma...

Estas lagunas han hecho que la magnífica eclesiología de comunión del Vaticano II, en la práctica, haya quedado muchas veces a mitad de camino por falta de mediaciones eclesiales concretas para llevarlas a su realización. Muchos de estos temas se convertirán en el postconcilio, sobre todo en tiempo de Pablo VI, en cuestiones no sólo candentes sino conflictivas. Pensemos, por ejemplo, en la polémica surgida en torno a la Humanae vitae.

\section{De la primavera al invierno ecclesial}

Añadamos a lo anterior que el poner en práctica el Vaticano II, luego de quince siglos de Constatinismo eclesial, produjo muchas reacciones y exageraciones en el seno de la Iglesia. Desde la sociología, en concreto desde la sociología religiosa, esto no debería extrañarnos, pues una gran masa de fieles no cambia rápidamente de su modo tradicional de pensar y de actuar.

Algunos sectores muy conservadores se resistieron a aceptar el Vaticano II, creyeron que la Iglesia doblaba sus rodillas ante la Modernidad (J. Maritain, L. Bouyer...).

Mucho peor y más intransigente fue la postura del Mons Marcel Lefèbvre que acabó formando un grupo disidente (Fraternidad de Pío X) y que fue personalmente excomulgado por Juan Pablo II (1988) al proceder Lefèbvre a nombrar sus propios obispos. La cuestión litúrgica (el deseo de volver a la liturgia latina de Pío V) no fue lo más importante: en el fondo había un rechazo frontal del Vaticano II al que se acusaba de protestantismo y modernismo. Conocemos toda la evolución que ha ido teniendo este grupo hasta nuestros días y los difíciles caminos de reconciliación. Si para algunos de ellos el Vaticano II fue una auténtica cloaca, ¿cómo poder dialogar con ellos?

Estas posturas críticas estaban también influidas por la deficiente hermenéutica y recepción del Concilio por otros grupos opuestos. Hubo de 
parte de algunos sectores de la Iglesia una interpretación excesivamente libre y alegre del Vaticano II, lo cual produjo excesos, abusos y exageraciones en terrenos dogmáticos, litúrgicos, morales, ecuménicos... y lo que fue más doloroso, el abandono del ministerio por parte de muchos sacerdotes y de muchos miembros de la vida consagrada. A esto se sumó un descenso de la práctica dominical y sacramental, divorcios, el aumento de indiferencia religiosa, el descenso entre las vocaciones sacerdotales y religiosas, un ambiente muy secularizado y crítico frente a la Iglesia...

Esto explica el hecho de que dentro de personas muy responsables y representativas de la Iglesia se hiciera una crítica si no del Vaticano II, sí ciertamente de su aplicación. Aquí hay que señalar la entrevista que tuvo el Cardenal Joseph Ratzinger, entonces Prefecto de la Congregación de la fe, con el periodista italiano Vittorio Messori en 1985 (MESSORI; RATZINGER, 1985). Ratzinger no critica al Concilio sino al anti-espíritu del Concilio que se ha introducido en la Iglesia, fruto de los embates de la modernidad y de la revolución cultural sobre todo de Occidente. No defiende una vuelta atrás sino una restauración eclesial, una vuelta a los auténticos textos conciliares para buscar un nuevo equilibrio y recuperar la unidad y la integridad de la vida de la Iglesia y de su relación con Cristo. No se siente muy inclinado a resaltar la historicidad de la Iglesia, ni los signos de los tiempos, ni el concepto de Pueblo de Dios, ni a apoyar las conferencias episcopales que le parece que asfixian el papel del obispo local. Cree que los últimos veinte años después del Concilio han sido desfavorables para la Iglesia y opuestos a las expectativas de Juan XXIII. Ni la teología liberadora de América Latina, ni las religiones no cristianas, ni el movimiento feminista gozan de su simpatía. El tono del diálogo es más bien pesimista y sombrío, mientras que para él un rayo luminoso de esperanza lo constituyen los nuevos movimientos laicales y carismáticos ${ }^{3} .$.

Frente a esta postura crítica de Ratzinger sobre el postconcilio, el cardenal de Viena, Franz König, que jugó un papel muy importante en el Vaticano II, escribió un libro, Iglesia, ¿adónde vas? (KÖNIG, 1986) que

3 Para comprender el pensamiento teológico de J. Ratzinger puede ayudar el texto de GORDO, J. M. La cristología de Josef Ratzinger-Benedicto XVI a la luz de su biografía teológica. Cuadernos Cristianisme i Justicia, n. 158, p. 153-158, 2008. 
afirma que la minoría conciliar veía el Concilio como una amenaza y utilizó todo su poder para vaciarlo de contendido. Para König, la Iglesia de hoy, sin el Vaticano II, habría sido una catástrofe y son un tanto sospechosos los intentos actuales de restauración eclesial.

El Sínodo de obispos de 1985 convocado por Juan Pablo II defendió la identidad del Vaticano II frente a sus impugnadores, no obstante sustituyó el concepto de Pueblo de Dios por el de Iglesia Cuerpo de Cristo, resaltó la importancia de la santidad y de la cruz en la Iglesia (seguramente creyendo que Gaudium et spes era demasiado optimista y humanista), sustituyó la palabra pluralismo por la de pluriformidad, e intentó leer Gaudium et spes desde Lumen Gentium y no al revés.

Se ha dicho que la minoría conciliar, que fue "derrotada" en el Vaticano II, poco a poco ha ido enarbolando la interpretación y conducción del Vaticano II. Lentamente hemos ido pasando de la primavera al invierno conciliar (K. Rahner), a una vuelta a la gran disciplina (J. B. Libanio), a una restauración eclesial (J. C. Zízola), a una noche oscura eclesial (J. I. González Faus). A la revista Concilium, liderada por los grandes teólogos conciliares, se le añade en 1972 la revista Communio inspirada por Hans Urs von Balthasar con una línea teológica diferente. Von Balthasar parece constituirse en la gran figura teológica del post-Concilio, como lo fue Rahner del Concilio. Algo está cambiando.

Muchos de los documentos eclesiológicos del magisterio que se han ido produciendo en tiempo de Juan Pablo II, como Apostolos suos (1998) sobre las conferencias episcopales, Communionis notio (1992) sobre las Iglesias locales, la Instrucción sobre la colaboración de los fieles laicos en el ministerio de los sacerdotes (1987), marcan un claro retroceso respecto a la inspiración más profunda del Vaticano II.

En cambio, hay que reconocer que al final de pontificado de Juan Pablo II hay algunos gestos de apertura, como la reunión de Asís con los representantes de todas las religiones (1986), la invitación a repensar entre todos los cristianos el ejercicio actual del primado de Pedro en la Iglesia (Ut unum sint, 1996), la petición de perdón de los pecados de la Iglesia en el segundo milenio en el año del jubileo del 2000 y la Instrucción Dominus Jesus (2000), que, aunque su contenido sea conservador, implica que se capta la importancia, urgência y novedad del diálogo inter-religioso. 
A casi 50 años de la clausura del Concilio, algunos se preguntan si en el Concilio realmente sucedió algo (SCHULTENHOVER, 2007). Frente a esta postura un tanto crítica y dubitativa, los estudios históricos dirigidos por G. Alberigo (ALBERIGO, 1999-2008) han demostrado fehacientemente que el Vaticano II fue un verdadero "acontecimiento". Pero no han faltado reacciones en contra, como la de Mons. A. Marchetto, para quien el Vaticano II no opera ninguna ruptura con el pasado, sino que es preferible hablar de continuidade (MARCHETTO, 2008, p. 111-127). El mismo Benedicto XVI prefiere hablar de reforma sin ruptura (BENEDICTO XVI, 2005).

\section{Cambio de acentos}

Pero sin dejar de lado las diversas hermenéuticas y aplicaciones del Vaticano II, si nos fijamos en el nuevo contexto socio-eclesial que hoy vivimos, constataremos que ha habido como un corrimiento de acentos y de interés en la apreciación y actualidad de los mismos documentos conciliares.

Para poner algún ejemplo, si la eclesiología del Vaticano II estuvo centrada en Lumen gentium (una Iglesia ya constituída), hoy día vemos que el decreto Ad gentes sobre la actividad misionera de la Iglesia recobra mayor actualidad y urgencia y esto no sólo para los llamados "países de misión" sino también y quizás sobre todo para los mismos países de tradición católica, convertidos hoy en verdaderos países de misión, donde es necesaria una nueva evangelización. ¿Es casual que el próximo Sínodo de obispos tenga como tema la Nueva evangelización?

El ecumenismo conciliar, expresado sobre todo en el decreto Unitatis redintegratio, parece quedar un tanto desplazado ante la actualidad del diálogo inter-religioso que el mismo Vaticano II propició em su decreto Nostra Aetate. ¿Qué sentido y urgência tienen las discusiones domésticas entre cristianos ortodoxos, evangélicos y anglicanos, cuando el grave problema es la relación con las grandes mayorías no cristianas? Toda la problemática ecuménica, evidentemente no desaparece, pero queda como en un segundo lugar ante los problemas religiosos y políticos del diálogo con el Islam, Hinduismo, Budismo, Judaísmo y las religiones 
originarias, lo que algunos llaman macro-ecumenismo, aunque a otros disgusta este nombre.

Para poner outro ejemplo intra-eclesial, las discusiones en torno a la Nota previa introducida un tanto misteriosamente al final de la Lumen gentium sobre la relación entre primado y colegialidad episcopal, quedan hoy muy relativizadas y como desplazadas ante el pedido del mismo Juan Pablo II en su encíclica Ut unum sint (1995) de que dirigentes y teólogos de las diferentes Iglesias y comunidades cristianas le ayuden a reformular el ejercicio del primado petrino hoy, para que, sin renunciar a su misión de servicio a la comunión, deje de constituir un obstáculo (¿el principal?) para la unión de los cristianos.

¿Qué está sucediendo? ¿Cómo interpretar estos cambios que afectan al mismo ser eclesial?

\section{De la eclesiología al problema de Dios}

Más allá de las buenas o malas voluntades, más allá de las diferentes ideologías y de las diferentes hermenêuticas en torno al Vaticano II, hay que reconocer que hoy estamos ante un cambio de época, estamos entrando en una crisis de cultura mundial, no precisamente destructiva, pero sí de proporciones inéditas.

Antropólogos, sociólogos, filósofos e historiadores reconocen que vivimos una situación nueva, una especie de tsunami, de terremoto global, que afecta a todas las dimensiones de nuestra existencia: sociales, económicas, políticas, culturales y también religiosas y espirituales. La generalización y aceleración de las comunicaciones, la globalización de flujos energéticos y de los recursos, la movilidad de las personas, el impacto creciente e inesperado de la ciencia, la amenaza de la degradación del planeta, nos producen la impresión de caos generalizado.

Si hace algunos años todavía se soñaba en el Estado de bienestar, actualmente todo el mundo vive en una atmósfera de inseguridad, de incertidumbre y precariedad. La llamada "época axial" o el "tiempo eje" que desde el 900 a. C. hasta el 200 a. C. configuró la sabiduría y cosmovisión religiosa de China (Confucio), India (Buda), Grecia (Sócrates) e Israel (Isaías, Jeremías y 
los profetas), (ARMSTRONG, 2007) hoy ha entrado en una profunda crisis, se necesita elaborar un "segundo tiempo axial" (K. Jaspers), o mejor aún, hay que reconocer que ya estamos vivendo em un nuevo tiempo axial.

Todo esto naturalmente afecta a nuestra conciencia religiosa y eclesial. J. B. Metz ha formulado en una especie de sorites los cambios que vivimos a nivel religioso y eclesial. Frente a una época de pertenencia pacífica a la Iglesia, hoy hemos ido passando primero a afirmar "Cristo sí, Iglesia no", para luego ir avanzando a "Dios sí, Cristo, no" y más adelante "religión sí, Dios, no", para acabar diciendo "espiritualidade sí, religión no".

En este clima caótico de cambio e incertidumbre generalizada, la problemática del Vaticano II ha quedado de algún modo desplazada o incluso superada. Ya no tiene mucho sentido seguir discutiendo sobre ritos litúrgicos, la curia vaticana, la disminución de la práctica dominical, el control de natalidad, la comunión a los divorciados o las parejas homosexuales...Los problemas son mucho más radicales y de fondo. Las generaciones jóvenes son las que más lo perciben y sufren.

El Vaticano II fue un concilio fuertemente eclesiológico, centrado em la Lumen gentium y en la Gaudium et spes. Respondía a la pregunta que Pablo VI había lanzado a los padres conciliares: "Iglesia ¿qué dices de ti misma?" Todos los demás documentos giran en torno a la Iglesia o convergen en ella: revelación, liturgia, laicado, Pueblo de Dios, jerarquía, vida religiosa, ecumenismo, diálogo con el mundo moderno etc.

Pero pocos años después del Vaticano II, el mismo Pablo VI, en una semana social de Francia, cambió la pregunta del Concilio y la convirtió en esta otra: "Iglesia ¿qué dices de Dios?"

El teólogo y cardenal Walter Kasper reconoce que el Vaticano II se limitó demasiado a la Iglesia y a las mediaciones eclesiales y descuidó de atender al verdadero y auténtico contenido de la fe, a Dios (KASPER, 2007, p. 414).

Y Rahner llegó a afirmar que el concilio Vaticano I había sido más audaz que el Vaticano II al haberse atrevido a tratar la cuestión del mistério inefable de Dios. Y a este propósito escribió:

El futuro no preguntará a la Iglesia por la estructura más exacta y bella de la liturgia, ni tampoco por las doctrinas teológicas controvertidas que 
distinguen la doctrina católica de los cristianos no católicos, ni por un régimen más o menos ideal de la curia romana. Preguntará si la Iglesia puede atestiguar la proximidad orientadora del mistério inefable que llamamos Dios. [...] Y por esta razón, las respuestas y soluciones del pasado Concilio no podrían ser sino um comienzo muy remoto del quehacer de la Iglesia del futuro (RAHNER, 1966, p. 22).

La Iglesia ha de concentrarse en lo esencial, volver a Jesús y al evangelio, iniciar una mistagogía que lleve a una experiencia espiritual de Dios, es tiempo de espiritualidad y de mística. Y también de profecía frente al mundo de los pobres y excluidos que son la mayor parte de la humanidad, y frente a la tierra, la madre tierra, que está seriamente amenazada. Mística y profecia son inseparables. La Iglesia ha de generar esperanza y sentido a un mundo abocado a la muerte.

No es tiempo de retoques parciales, estamos en um tiempo que recuerda al que precedió inmediatamente a la Reforma. Hay que ir a lo esencial. Y no engañarnos, no caer en la vieja tentación de tocar violines mientras el Titánic se hunde...La Iglesia ha de ser una comunidade mistagógica (VITORIA, 2009, p. 163-193), una comunidade hermenéutica, que sea mediación y no obstáculo para el encuentro con el Dios de Jesús.

\section{Del caos al kairós}

En este clima de perplejidad y de crisis universal, los cristianos afirmamos que en medio de este caos, está presente la Ruah, el Espíritu que se cernía sobre el caos inicial para generar la vida, el mismo Espíritu que engendró a Jesús de Maria Virgen y lo resucitó de entre los muertos. Del caos puede surgir un tiempo de gracia, um kairós, una Iglesia renovada, nazarena, más pobre y evangélica.

Algunas voces postulan um nuevo concilio, pero en la actual situación eclesial y con el episcopado nombrado em las últimas décadas, um nuevo concilio tendría el gran riesgo de ser sumamente conservador y tradicionalista, nostálgico de la época de cristiandad del segundo milenio...

Habrá que esperar mejores coyunturas de futuro, confiar en la fuerza del Espíritu que sigue guiando a la Iglesia. Y en todo caso, no debería 
convocarse un Vaticano III, al estilo de los anteriores sínodos de la Iglesia occidental, sino algo diferente y nuevo, un concilio verdaderamente ecuménico, un Jerusalén II...

\section{Referencias}

ALBeRIGO, G. (Ed.). Historia del Conclio Vaticano II, I-V. Salamanca: Santander, 1999-2008.

ALMEIDA, A. J. de. A transição necessária. São Paulo: Lumen Gentium, 2005. ARMSTRONG, K. La gran transformación. Barcelona: Paidós, 2007.

BENEDICTO XVI. Discurso de felicitación de Navidad a la curia romana. 2005. Disponível em: <http://www.vatican.va/holy_father/benedict_xvi/ speeches/2011/december/documents/hf_ben-xvi_spe_20111222_auguri-curia_sp.html >. Acesso em: 21 jun. 2011.

CODINA, V. Para comprender la eclesiología desde América Latina. Estella, Navarra: Verbo Divino, 2008.

GORDO, J. M. La cristología de Joseph Ratzinger-Benedicto XVI. A la luz de su biografía teológica. Cuadernos Cristianisme i Justicia, n. 158, p. 153-158, 2008.

KASPER, W. El desafío permanente del Vaticano II. Hermenéutica de las aseveraciones del concilio. In: KASPER, W. Teología e Iglesia. Barcelona: Herder, 1989. p. 401-415.

KÖNIG, K. Iglesia ¿adónde vas? Salamanca: Santander, 1986.

MARCHETTO, A. El Concilio Ecuménico Vaticano II: contrapunto para su historia. Valencia: Edicep, 2008.

MESSORI, V.; RATZINGER, J. Informe sobre la fe. Madrid: BAC, 1985.

RAHNER, K. El Concilio, nuevo comienzo. Barcelona: Herder, 1966. 
SCHULTENHOVER, D. G. (Ed.). Vatican II: Did anything happen? New York: Continuum, 2007.

VITORIA, F. J. No hay "territorio comanche” para Dios: accesos a la experiencia cristiana de Dios. Madrid: HOAC, 2009.

Recibido: 22/11/2011

Recebido: 22/11/2011

Aprobado: 29/01/2012

Aprovado: 29/01/2012 